\title{
FLAVITA BANANA: ARTE GRÁFICO, FEMINISMO Y HUMOR ${ }^{1}$
}

Flavita Banana ${ }^{2}$
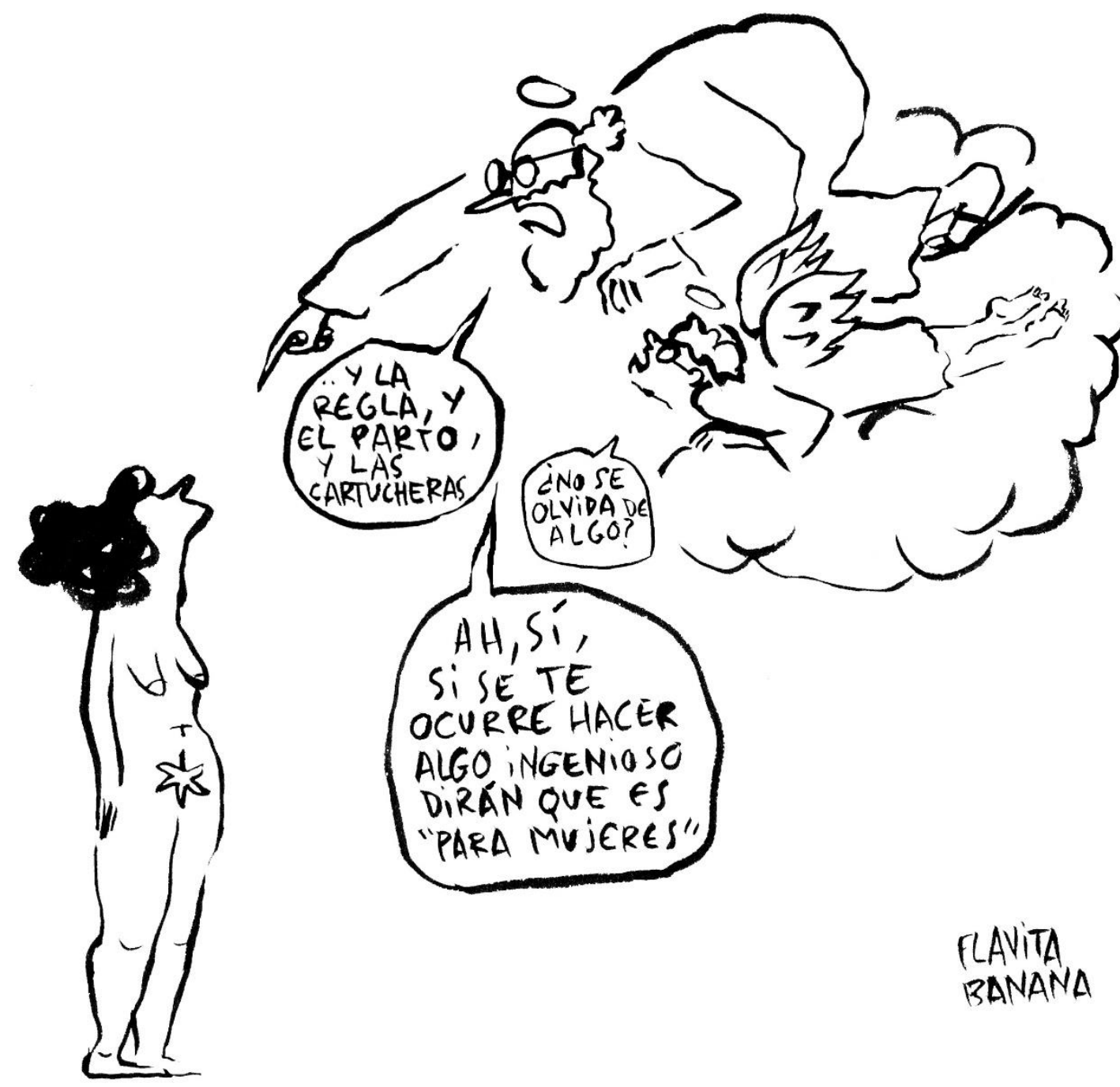

${ }^{1}$ Fecha de recepción: 15/12/2020.

Fecha de aceptación: 22/12/2020.

${ }^{2}$ Flavita Banana (Flavia Álvarez-Pedrosa) nació en 1987. Estudió Artes y Diseño, además del ciclo de Ilustración, en la Escola Massana de Barcelona. A los veintiséis años empezó a dibujar viñetas de humor y tres años más tarde ya colaboraba con $S$ Moda, Orgullo y Satisfacción, Revista Mongolia y El País. Como ilustradora, ha publicado los libros Curvy (Lumen, 2016) y como autora Las Cosas del Querer (Lumen, 2017), Archivos Estelares (¡Caramba!, 2017), Archivos Cósmicos (¡Caramba!, 2019) y Archivos Espaciales (¡Carambra!, 2020). En 2018 recibió el premio Gat Perich de humor gráfico; $\square$ flavitabanana@gmail.com. 

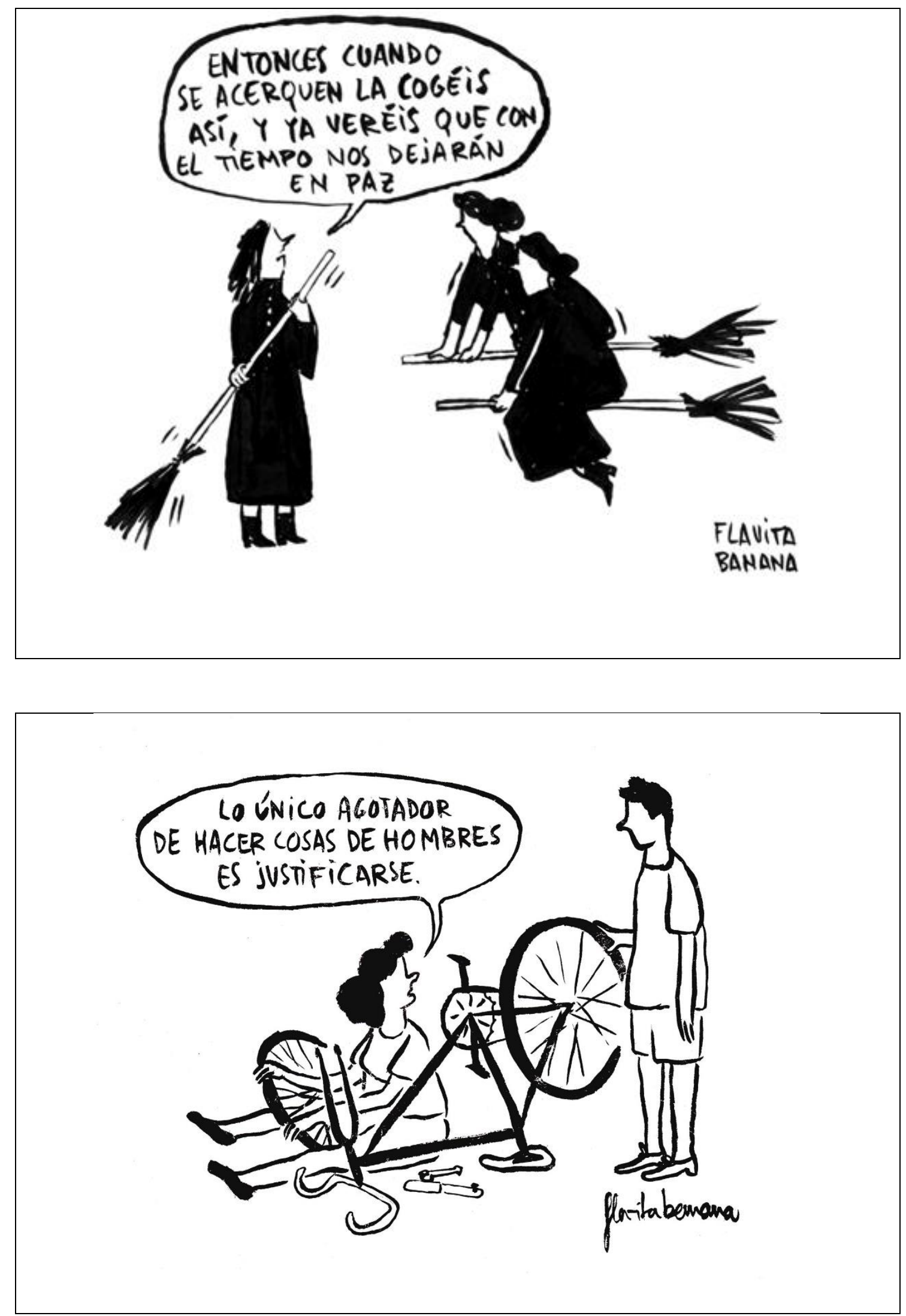

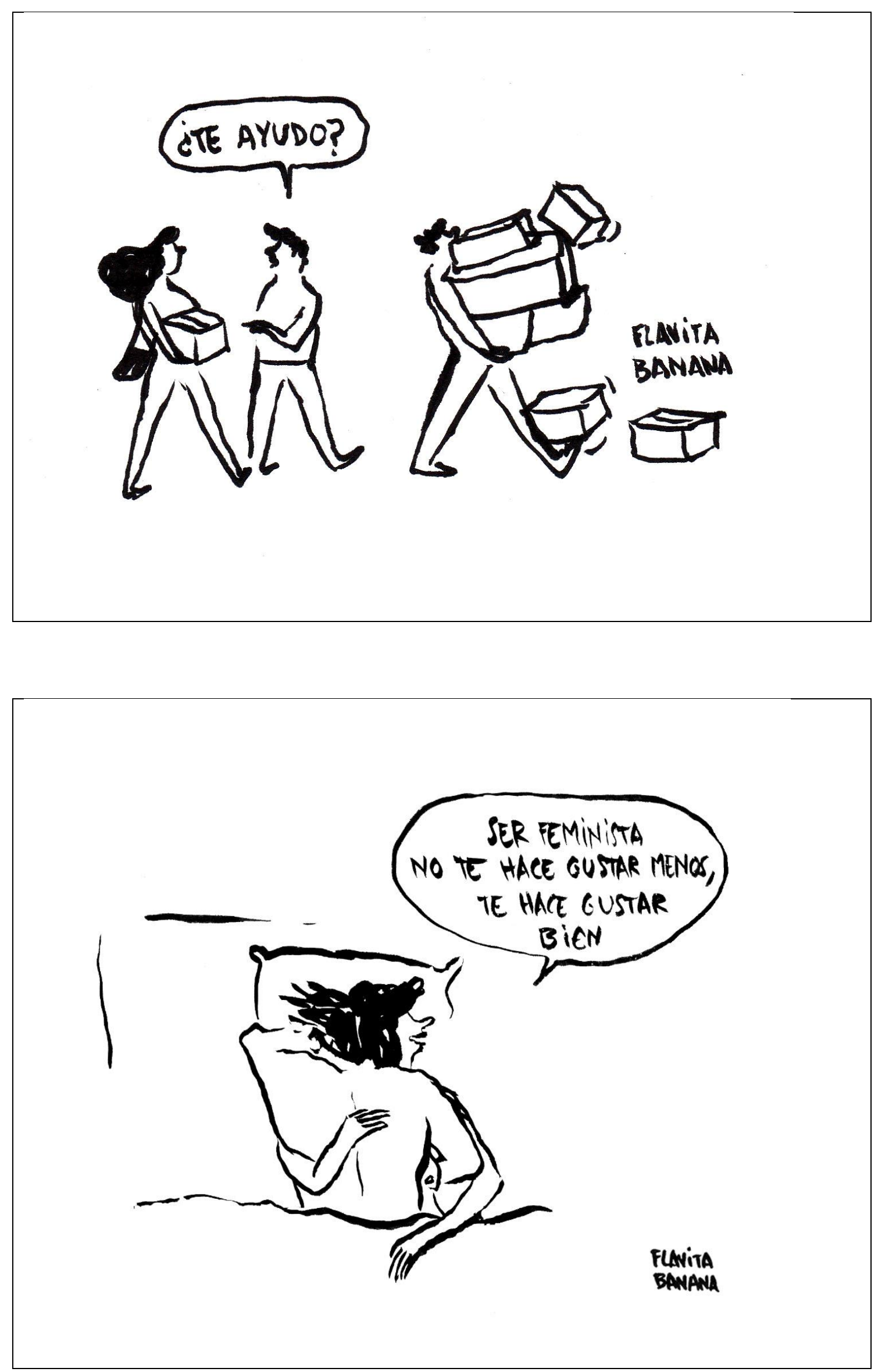


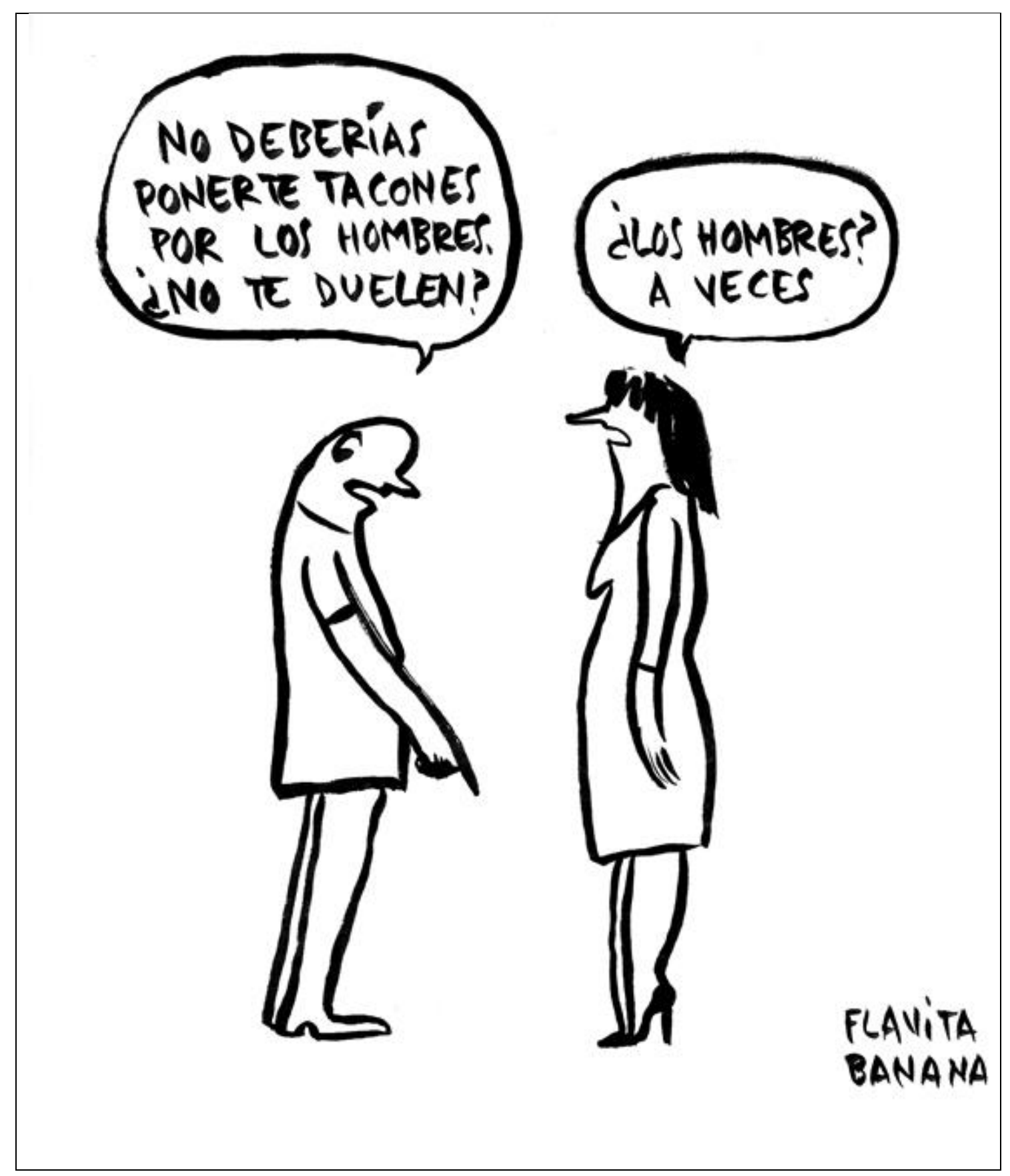

